\title{
AMCoR
}

Asahikawa Medical University Repository http://amcor.asahikawa-med.ac.jp/

Mol Cell Endocrinol. (2014.3) Volume 385, Issues 1-2,:88-96.

Functional implications of the Golgi and microtubular network in gonadotropes.

Tsuyoshi Watanabe, Hiroki Bochimoto, Daisuke Koga, Masahiro Hosaka, and Tatsuo Ushiki 


\section{Functional Implications of the Golgi and Microtubular Network in Gonadotropes}

Tsuyoshi Watanabe ${ }^{\mathrm{a}, *}$ Hiroki Bochimoto $^{\mathrm{a}}$, Daisuke Koga ${ }^{\mathrm{b}}$, Masahiro Hosaka ${ }^{\mathrm{c}}$, and Tatsuo Ushiki $^{b}$

${ }^{a}$ Department of Microscopic Anatomy and Cell Biology, Asahikawa Medical University, Asahikawa, Japan;

${ }^{b}$ Division of Microscopic Anatomy and Bio-imaging, Department of Cellular Function, Niigata University Graduate School of Medical and Dental Sciences, Niigata, Japan;

${ }^{c}$ Laboratory of Molecular Life Sciences, Department of Biotechnology, Akita Prefectural University, Akita, Japan

*Corresponding author

Department of Microscopic Anatomy and Cell Biology, Asahikawa Medical University, 2-1-1-1 Midorigaoka-higashi, Asahikawa 078-8510, Japan

E-mail: tyshwata@asahikawa-med.ac.jp

Tel: +81 166682310 / Fax: +81 166682319 


\begin{abstract}
In contrast to the widely accepted images of the Golgi apparatus as a cup-like shape, the Golgi in pituitary gonadotropes is organized as a spherical shape in which the outer and inner faces are cis- and trans-Golgi elements, respectively. At the center of the spherical Golgi, a pair of centrioles is situated as a microtubule-organizing center from which radiating microtubules isotropically extend toward the cell periphery. This review focuses on the significance of the characteristic organization of the Golgi and microtubule network in gonadotropes, considering the roles of microtubule-dependent membrane transport in the formation and maintenance of the Golgi structure. Because the highly symmetrical organization of the Golgi is possibly perturbed in response to experimental treatments of gonadotropes, monitoring of the Golgi structure in gonadotropes under various experimental conditions will be a novel in vivo approach to elucidate the biogenesis of the Golgi apparatus.
\end{abstract}

KEY WORDS: Golgi apparatus; Microtubule-organizing center (MTOC); Cellular polarity; Pituitary; Gonadotrope; GnRH signaling. 


\section{Introduction}

The pituitary gonadotrope is a representative endocrine cell that synthesizes and releases two distinct peptide hormones, luteinizing hormone ( $\mathrm{LH}$ ) and follicle-stimulating hormone (FSH). Besides these two gonadotropins, gonadotropes secrete a large amount of soluble proteins such as chromogranins and secretogranins (Chanat et al., 1988; Cozzi and Zanini, 1986). Morphologically, gonadotropes contain two different types of secretory granules, small granules containing secretogranin II and large granules containing chromogranin A (Hosaka et al., 2002; Watanabe et al., 1998, 1993, 1991). To generate a large amount of secretory granules containing hormones and related proteins, the endomembranous organelles that constitute the exo- and endo-cytic pathways are well developed/organized in gonadotropes.

Among the endomembranous organelles, the Golgi apparatus is situated at the center of the secretory pathway and functions as an intersection of intracellular vesicular transport. The Golgi apparatus was first identified as a reticular structure in neurons using a silver impregnation method to stain the cells (Golgi, 1898a, b). Later, the intracellular structure stained by the silver impregnation method was ubiquitously observed in various cells at light microscopic levels, although the debate on the reality of the organelle lasted for a long time (for reviews on the issue including related references, see Beams and Kessel, 1968; Farquhar and Palade, 1981). Observations under an electron microscope finally settled this dispute by demonstrating the distinct membrane set that constitutes the Golgi apparatus: flattened cisterns and associated vesicles/vacuoles corresponding to the reticular structure observed at the light microscopic level (Dalton and Felix, 1954; Farquhar and Rinehart, 1954; Sjöstrand and Hanzon, 1954)

Subsequent analyses clarified that the organelle plays a pivotal role in the processing and sorting of both soluble and transmembrane proteins passing through the secretory 
pathway (Farquhar and Palade, 1981, 1998; Marsh and Howell, 2002, Martinez-Alonso et al., 2013). During sequential transition in the stacks of Golgi cisterns, luminal proteins and lipids are modified by the action of Golgi-resident enzymes, including glycosylation (Moremen et al., 2012), sulfation (Huttner, 1988; Niehrs et al., 1994), and proteolytic processing (Halban and Irminger, 1994). Upon post-translational modification and processing, the proteins are sorted at the trans-Golgi network (TGN), the exit site of the Golgi apparatus, for their appropriate destinations such as the plasma membrane via secretory tubulovesicles, secretory granules, and lysosomal/endosomal compartments (De Matteis and Luini, 2008; Farquhar and Palade, 1998; Griffiths and Simons, 1986; Mellman and Simons, 1992). On the other hand, Golgi-resident enzymes are retained in the Golgi apparatus. Membrane-bound glycosyltransferases and other modifying enzymes that function in the Golgi apparatus are excluded and/or removed from membrane carriers forwarding to the secretory pathways (Allan and Balch, 1999; Glick et al., 1997; Opat et al., 2001; Pelham, 2001; Puthenveedu and Linstedt, 2005; Storrie, 2005). In any case, the incessant traffic of tubulovesicular carriers that move along microtubules both in antero- and retro-grade directions largely affect the organization of the Golgi apparatus (Brownhill et al., 2009; Cole and Lippincott-Schwartz, 1995).

Because the flattened cisterns of the Golgi apparatus are stacked in order forming a cup-like or hemispherical shape in exocrine cells that secrete a large amount of proteins in a polarized manner, the fundamental configuration of the Golgi apparatus has been widely accepted as a cup-like/hemispherical shape. Cisterns at the convex and concave faces of the cup-like Golgi stacks are designated as cis- and trans- cisterns that functionally face the rough endoplasmic reticulum (ER) and cell surface, respectively (Farquhar and Palade, 1981; Mellman and Simons, 1992). This organization of the Golgi stacks can explain the vectorial 
movements of secretory products from the rough ER to their final destinations at the cell periphery.

On the other hand, diversity in the higher organization of the Golgi apparatus depending on the cell/tissue type has been recognized by various microscopic techniques. In the drawings of the earliest studies by light microscopy, the overall shape of the Golgi apparatus is not described as cup-like, but rather a spheroidal network, even in the original drawings of neurons by Golgi (Golgi 1898a, b). The ultrastructural characteristics and diversities of the three-dimensional architecture of the Golgi apparatus were extensively demonstrated by Rambourg and his colleagues by stereograms of a pair of tilted images from high voltage transmission electron microscopy (Clermont et al., 1995; Rambourg and Clermont, 1997, 1990; Rambourg et al., 1993, 1992, 1981). Through their comprehensive observation and later detailed studies with the aid of computerized tomographic reconstruction (Marsh, 2005; Marsh et al., 2004; Mogelsvang et al., 2004), the higher level organization of the Golgi apparatus is now accepted as a continuous ribbon-like structure in various configurations with compact and non-compact regions. Compact regions consist of piled stacks of Golgi cisterns with convex (cis-) and concave (trans-) sides that are linked to each other by a sparse tubular network defined as the non-compact region (Klumperman, 2011; Rambourg and Clermont 1990). Observations of osmium-macerated specimens under a high resolution scanning electron microscope has also revealed the diversity of the overall three-dimensional ultrastructure of the Golgi apparatus in various mammalian cells (Koga and Ushiki, 2006; Tanaka and Fukudome, 1991; Tanaka and Mitsushima, 1984; Tanaka et al., 1986). However, the profound mechanisms that promote structural diversity of the Golgi apparatus in vivo remain to be solved. 
To shed light on this issue, our review focuses on the structural characteristics of the Golgi apparatus and microtubule network in pituitary gonadotropes, and attempts to illustrate the significance behind the distinctive organization. We also discuss the putative crosstalk between gonadotropin-releasing hormone $(\mathrm{GnRH})$ signaling and the functional molecules that maintain the Golgi organization, based on structural changes of the Golgi apparatus after stimulation of gonadotropes. In parallel, the putative links between cellular polarity and Golgi organization will be discussed by comparing the overall shape and intracellular location of the Golgi apparatus in gonadotropes with those in other endocrine and exocrine cells. The unique organization of the Golgi apparatus in pituitary gonadotropes possibly provides a clue to clarify the theoretical background behind the diversity of the overall shapes of the Golgi apparatus depending on the cell type.

\section{Structural characteristics of the Golgi apparatus and microtubule network within rat pituitary gonadotropes}

As shown in our recent studies, pituitary gonadotropes generally contain a Golgi apparatus with a globular shape (Figure 1A, B) in which the outer and inner surfaces are cis- (the entry side of the Golgi) and trans- (the exit side) faces, respectively (Figure 1C-E) (Koga and Ushiki, 2006; Watanabe et al., 2012). Immunocytochemical localization of BiP (indicative of rough ER; Figure 1C) and $\gamma$-adaptin (indicative of vesicles generated from the TGN; Figure 1E) indicate that the pre- and post-Golgi compartments in gonadotropes are mostly segregated from each other by the spherical walls of Golgi cisterns.

The overall shape of the Golgi apparatus in gonadotropes was demonstrated at the light microscopic level about a hundred years ago by staining with the silver impregnation method, although these earlier observations have been often disregarded. The shape of the 
Golgi apparatus in basophilic gonadotropes of the anterior pituitary has been described principally as round, which spherically enlarges after castration (Addison, 1917; Ellison and Wolfe, 1934; Severinghaus, 1937, 1933; Wolfe and Brown, 1942). Although the circular profile of the globular Golgi apparatus can be observed in electron micrographs of early studies focusing on pituitary gonadotropes (Farquhar and Rinehart, 1954; Kurosumi and Oota, 1968; see also chapter 4 "Gonadotropes" in Costoff, 1973), little attention has been paid to the significance of its globular shape.

To realize the significance of the globular configuration of the Golgi apparatus in pituitary gonadotropes, the intracellular organization of the microtubule network should be considered because the positioning, orientation, and overall configuration of the Golgi apparatus are largely determined by the balance of membrane input and output transported via microtubule-dependent motor proteins (Allan et al., 2002; Brownhill et al., 2009; Cole and Lippincott-Schwartz, 1995; Lippincott-Schwartz, 1998; Murshid and Presley, 2004; Thyberg and Moskalewski, 1999). As described in our recent study, a pair of centrioles immunolabeled with anti- $\gamma$-tubulin antibodies is situated at the center of the spheroidal Golgi apparatus as a microtubule-organizing center (MTOC) (Figure 1B, F) from which radiating microtubules extend in all directions toward the cell periphery through gaps in the spheroidal wall of the Golgi stack (Watanabe et al., 2012). In addition to these radiating microtubules, relatively stable microtubules immunolabeled with anti-acetylated $\alpha$-tubulin antibodies accumulate on the outer surface of the spherical Golgi (Figure 1F, G). Thus, the architecture of the microtubule network in gonadotropes appears to be much more isotropic than that of exocrine cells (Kurihara and Uchida, 1987), probably because the sites for exocytotic secretion are less strictly confined to specialized subdomain(s) on the cell surface. 
Considering the contextual usage of microtubule-dependent motors and tubulovesicular membrane carriers, both the cis-trans orientation and characteristic shape of the Golgi apparatus in gonadotropes can be rationally explained. The motor proteins that drive intracellular transport carriers along the microtubules are classified into two discrete categories: plus and minus end-directed motors (Gennerich and Vale, 2009; Hirokawa, 1998; Schliwa and Woehlke, 2003). In general, dyneins move toward the minus end of microtubules and mediate the centripetal movements of tubulovesicular carriers ((Pfister et al., 2005; Vallee et al., 2004; Yadav and Linstedt, 2011), while kinesins (and most kinesin superfamily proteins [KIFs]) move toward the plus end of microtubules and mediate centrifugal movements (Hirokawa and Noda, 2008; Lawrence et al., 2004).

These two types of microtubule-dependent motor proteins are specifically associated with their corresponding membrane carriers in pre- and post-Golgi compartments, and contribute to the well-coordinated movements of these carriers in the cell (Brownhill et al., 2009; Goodson et al., 1997; Hehnly and Stamnes, 2007). In the pre-Golgi compartment (Figure 2B), coat protein complex (COP)II-coated vesicles carried by dynein motors mediate anterograde transport from the ER to the Golgi (Harada et al., 1998; Presley et al., 1997; Watson et al., 2005), while COPI-coated tubulovesicles that use kinesin/KIF motors mediate retrograde transport from the Golgi to the ER (Dorner et al., 1998; Lippincott-Schwartz et al., 1995; Stauber et al., 2006). In the post-Golgi compartment (Figure 2C), secretory granules/tubulovesicles and newly generated primary lysosomes are likely transported by kinesin/KIFs for anterograde traffic from the Golgi (Jaulin et al., 2007; Kreitzer et al., 2000; Nakagawa et al., 2000; Varadi et al., 2002), while endocytosed tubulovesicles are likely transported mainly by dyneins for retrograde traffic from the plasma membrane to the central area of the cell near the trans-side of the Golgi (Blocker et al., 1997; Burkhardt et al., 1997; 
Loubery et al., 2008; see also a review by Hunt and Stephens, 2011). Considering that microtubules isotropically radiate from a single MTOC at the cell center and the Golgi apparatus is formed in the middle along these radiating microtubules, this simple architecture of the microtubule network can systematically explain the peculiar polarity of the Golgi apparatus and all intracellular membrane trafficking within gonadotropes. The minus end-directed motors such as dyneins mediate the centripetal movements of the carriers, COPII-coated vesicles, and endocytosed tubulovesicles in pre- and post-Golgi compartments, while plus end-oriented motors such as kinesin/KIFs mediate the centrifugal movements of the carriers, the COPI-coated vesicles, and secretory granules/tubulovesicles in pre- and post-Golgi compartments (Figure 2).

In addition to the trafficking lines within gonadotropes, the symmetrical globular shape of the Golgi apparatus in gonadotropes can also be explained based on the isotropic architecture of the microtubule network. As discussed above, Golgi cisterns are likely formed at the position where the membrane input and output to and from the Golgi apparatus are balanced (Cole and Lippincott-Schwartz, 1995; Lippincott-Schwartz, 1998). Geometrically, such balanced positions in gonadotropes are likely to be arrayed spherically at a certain distance from the single central MTOC. Thus, the cis-trans orientation and globular shape of the Golgi apparatus in gonadotropes can be regarded as an ideal model for poorly polarized endocrine cells.

Because the characteristic structure of the Golgi apparatus in gonadotropes largely depends on the microtubule architecture as discussed above, the organization of the Golgi is possibly altered by compounds that affect microtubule dynamics. Based on our preliminary observations, the most rapid morphological change in gonadotropes treated with colchicine, which disturbs microtubule dynamics by tightly binding to the intradimeric $\alpha-\beta$ interface of 
tubulin heterodimers (Stanton et al., 2011), is the appearance of atypical vacuoles in the peripheral region of cells (unpublished data). These vacuoles are widely observed in pituitary endocrine cells including gonadotropes at 30-60 minutes after intraperitoneal injection of rats with colchicine. Moreover, there is accumulation of specific marker proteins for the pre-Golgi compartment, such as ERGIC-53 (Schindler et al., 1993; for a review, see also Appenzeller-Herzog and Hauri, 2006) and p23 (Rojo et al., 1997; Hosaka et al., 2007; for a review, see also Emery et al., 1999), on their membrane. In contrast, the lateral integrity of the Golgi apparatus is preserved as the spherical configuration at this time point, but the Golgi cisterns gradually shrink after a certain delay and finally break into small dispersed stacks at 8 hours after treatment. These findings suggest that the kinetics of microtubule-dependent transport carriers are considerably different in pre- and post-Golgi compartments. The trafficking processes in the pre-Golgi compartment appear to be much more sensitive to colchicine treatment than those in the post-Golgi compartment. Although the mechanisms behind this phenomenon should be investigated further, the spatial segregation of pre- and post-Golgi compartments and the spherical wall of Golgi stacks in gonadotropes may help us to divide the influence of colchicine into two different steps in preand post-Golgi compartments. The distinct intracellular organization of gonadotropes is potentially beneficial for further analyses of vesicular transport processes along microtubules in vivo.

\section{Influences of extrinsic stimuli to the GnRH receptor on the organization of the Golgi in pituitary gonadotropes}

The functional states of pituitary gonadotropes are largely regulated by $\mathrm{GnRH}$ released from hypothalamic neurons into the hypothalamic-hypophyseal portal vascular system. GnRH 
specifically binds to the corresponding GnRH receptor expressed on pituitary gonadotropes, and subsequently stimulates cells to synthesize and release secretory products including two gonadotropins (for reviews see: Bliss et al., 2010; Naor, 2009; Ruf et al., 2003). Castration of experimental animals increases the intrinsic GnRH level released from hypothalamic neurons by impairing the negative feedback control of gonadal sex steroids (Pielecka and Moenter, 2006). Although chronic enlargement of the Golgi apparatus in pituitary gonadotropes of castrated animals has been reported (Addison, 1917; Ellison and Wolfe, 1934; Farquhar and Rinehart, 1954; Severinghaus, 1933; Wolfe and Brown, 1942), the immediate alteration of the Golgi structure after castration has been overlooked to date. The morphological effects of synthetic GnRH agonists on the Golgi apparatus in gonadotropes have been also scarcely examined until our most recent study (Bochimoto et al., 2013).

GnRH agonists generated by substitution of amino acid residues of intrinsic GnRH initially augment the intracellular signaling events downstream of its receptor (Conn and Crowley, 1994; Millar et al., 2004). Because sustained treatment with powerful GnRH agonists such as buserelin (Brogden et al., 1990) and leuprorelin (Plosker and Brogden, 1994) can paradoxically suppress synthesis and secretion of gonadotropins by receptor desensitization (McArdle et al., 2002; Naor, 2009), depot formulations of these GnRH agonists have been clinically used to deplete gonadal sex steroids in patients suffering from sex steroid-dependent diseases such as metastatic prostate cancer (Conn and Crowley, 1994; Engel and Schally, 2007). However, depot formulations of GnRH agonists potentially induce a flare effect caused by their own strong stimulatory effects on gonadotropes and the subsequent transient increase of serum sex steroids at the beginning of treatment (Conn and Crowley, 1994). Although gonadotropes are a direct target of these agonists, the 
ultrastructural changes in pituitary gonadotropes under the influence of GnRH agonists have been poorly analyzed until recently.

The configuration and ultrastructure of the Golgi apparatus in pituitary gonadotropes are largely affected by treatment with the depot formulation of the GnRH agonist leuprorelin. The ball-like shape of the Golgi apparatus in gonadotropes of control rats (Figure 3A, B) is transiently disrupted into a mini-stack from 1 day after administration of the leuprorelin depot formulation (Figure 3C, D), although the Golgi apparatus later coalesces again into a globular shape by 7 days of treatment (Bochimoto et al., 2013). Because similar changes in the Golgi apparatus are observed shortly after castration (Koga et al., unpublished observation), this transient disruption of the Golgi apparatus possibly occurs in response to intensive stimulation of the GnRH receptor.

Similar disorganization of the Golgi apparatus has been well analyzed and documented in cells during the mitotic phase of the cell cycle (Persico et al., 2009). The process of disassembly of the Golgi apparatus during mitosis is principally divided into two successive but distinct steps: unlinking of the Golgi ribbon and fragmentation of the Golgi cisterns into tubulovesicles. During late G2 phase preceding mitosis, highly organized Golgi ribbons are severed into isolated small pieces of the Golgi stack because of dispersion of non-compact regions interlinking the solid Golgi stacks of compact regions (unlinking of the Golgi ribbon). Following the unlinking of the Golgi ribbon, each isolated stack of cisterns is further broken down into tubulovesicles during mitosis (fragmentation of the Golgi stacks). Disorganization of the Golgi apparatus in acutely stimulated gonadotropes resembles the unlinking of the Golgi ribbon described above.

In the molecular mechanisms of the first unlinking step during mitotic changes in the Golgi apparatus, phosphorylation of Golgi-associated proteins plays a crucial role (Preisinger 
and Barr, 2005). Unphosphorylated Golgi reassembly stacking proteins (GRASPs) are able to laterally tether membranes of adjacent compact Golgi stacks by their trans-dimerization (Feinstein and Linstedt, 2008; Puthenveedu et al., 2006) and thus contribute to formation and maintenance of the overall organization of the Golgi apparatus as a ribbon (Lowe, 2011; Vinke et al., 2011). However, GRASPs are potential substrates of various kinases such as mitotic kinases Cdk1-cyclin B and polo-like kinase 1 (Lin et al., 2000; Wang et al., 2003), and extracellular-activated protein kinases (ERKs) (Jesch et al., 2001). Phosphorylated GRASPs are forced to dissociate from adjacent partner GRASPs, resulting in the breakdown of the link between two adjacent units of the Golgi stacks (Feinstein and Linstedt, 2008; Xiang and Wang, 2010).

GnRH released from hypothalamic neurons into hypothalamic-pituitary portal circulation can successively provoke intracellular signaling events within pituitary gonadotropes, including activation of kinases in MAPK signaling cascades (Bliss et al., 2010; Naor, 2009). Thus, Golgi-associated proteins including GRASPs are possibly phosphorylated by activated kinase(s), resulting in the scattering of isolated small Golgi stacks throughout gonadotropes as observed in the acute phase of GnRH agonist depot treatment. A recent study demonstrated that novel protein kinases C (nPKC) delta and epsilon, which activate ERKs in response to GnRH, are partially colocalized with GRASP65 in the Golgi apparatus of gonadotrope-derived cell lines, and are translocated to the perinuclear zone and plasma membrane, respectively, after GnRH stimulation (Dobkin-Bekman et al., 2010). These findings apparently support a putative link between GnRH signaling and the molecules that regulate the structural integrity of the Golgi apparatus in gonadotropes.

In contrast to the disorganization of the Golgi apparatus during mitosis, the scattered Golgi stacks in the acute stimulatory phase converge again into a well-organized spherical 
configuration by 1 week after treatment (Bochimoto et al., 2013). The initial effect of stimulation of the GnRH receptor is gradually alleviated by adaptive responses occurring downstream of the GnRH signaling cascade(s) (McArdle et al., 2002; Naor, 2009). Thus, the transient increase of signals downstream of the GnRH receptor is probably not sufficient to provoke further fragmentation of Golgi cisterns following the unlinking of Golgi ribbons.

Although it should be further clarified which signaling molecules are activated downstream of the GnRH receptor and are responsible for transient disorganization of the Golgi apparatus, perturbation of rat gonadotropes by treatment with depot formulations of GnRH agonists possibly provide intriguing animal models to analyze the morpho-functional relationship of the Golgi apparatus. Because of its highly symmetrical organization, disassembly and/or deformation of the Golgi apparatus can be sensitively detected in pituitary gonadotropes under these experimental conditions.

\section{Diversity of the global organization of the Golgi and microtubule network}

\section{4-1. Diversity of the Golgi organization of pituitary endocrine cells}

In addition to gonadotropes, there are at least four more kinds of endocrine cells in the anterior pituitary: somatotropes, mammotropes, corticotropes, and thyrotropes. Although each type of endocrine cell synthesizes and secretes its own peptide hormone(s) in a regulated manner, the size, shape, and intracellular location of the Golgi apparatus vary depending on the cell type (Costoff, 1973; Severinghaus, 1937, 1933). Thyrotropes possess a Golgi apparatus with a large spheroidal shape comparable with that in gonadotropes, while somatotropes and mammotropes contain a much smaller Golgi apparatus. Compared with gonadotropes and thyrotropes, the shape of the Golgi apparatus is considerably distorted in most mammotropes, corticotropes, and some somatotropes. Despite its diverse size and shape, 
the Golgi apparatus in pituitary endocrine cells is commonly enclosed in a certain amount of cytoplasm as demonstrated in mammotropes by Rambourg and his colleagues (Rambourg et al., 1992). Furthermore, the MTOC is often situated in cytoplasm enclosed by Golgi ribbons.

Assuming that formation of the Golgi apparatus is based on the balance of input and output of membrane transport along microtubules and that the microtubule network is isotropically organized from a single central MTOC, which is identical to that in gonadotropes as discussed above, the reason why the Golgi apparatus of some pituitary endocrine cells is not symmetrically globular but is rather distorted is unknown. One possible explanation is that the Golgi shape correlates to the cell shape itself. Both the overall configuration of the Golgi apparatus and the cell contour of rat corticotropes are mostly irregular in the physiological state. In this case, intracellular organization of the other cytoskeletal elements such as actin and intermediate filaments possibly affect both the Golgi and cell shape.

Another possibility is that distortion of the overall shape of the Golgi apparatus is because of its proximity to the nucleus. Because the MTOC in most mammotropes and some somatotropes appears to be too close to the nucleus, the Golgi apparatus in these cells is greatly deformed by pressing against the nucleus (Figure 4A). In contrast, the Golgi apparatus in gonadotropes and thyrotropes is enough apart from the nucleus, and could be isotropically expanded (Figure 4B). According to our preliminary evaluation of the spatial distances between the nucleus and MTOC in each cell type by laser confocal microscopy, the average distances of these two structures in somatotropes and mammotropes are significantly smaller than those in gonadotropes and thyrotropes (unpublished data). As a result, the overall shape of the Golgi apparatus in mammotropes and somatotropes does not often appear to be ball-like, but rather cap-like on the nucleus. Although the mechanism that determines 
the positioning of the MTOC should be further clarified, the intracellular location of the MTOC likely contributes to the diversity of both the intracellular positioning and organization of the Golgi apparatus.

\section{4-2. Comparison of exocrine acinar cells and the acinus}

In contrast to the endocrine cells discussed above, the organization of the Golgi apparatus in polarized exocrine cells is widely accepted as a cup-like or hemispherical shape (Koga and Ushiki, 2006; Motta et al., 1997). In the intracellular architecture of the microtubule network of typical polarized epithelial cells, the MTOC is localized in the apical cytoplasm away from the nucleus (Kano et al., 2001), and the minus and plus ends of microtubules principally direct to the apical and basal surfaces of the cell, respectively (Kano et al., 2001; Meads and Schroer, 1995; Müsch, 2004; see also Figure 4C). On these microtubules along the longitudinal axis of the cell, motor proteins drive diverse tubulovesicular carriers to their proper destinations, resulting in establishment of cellular polarity on the cell surface (Drubin and Nelson, 1996; Müsch, 2004).

The Golgi apparatus in polarized exocrine cells is possibly formed at an appropriate position along the coherent and directional array of microtubules extending from the apical to basal regions of the cytoplasm. As a result, the slightly curved cisterns of the Golgi apparatus are stacked perpendicularly to the longitudinal axis of the polarized acinar cells, and the convex and concave faces of the Golgi stacks face the rough ER and apical plasma membrane, respectively (Farquhar and Palade, 1998, 1981).

Although the overall shape of the Golgi apparatus in individual exocrine acinar cells is quite different from that in pituitary gonadotropes, the merged Golgi structure of a whole exocrine acinus can be regarded as a sphere. The secretory lumen, around which MTOCs are 
located in the apical cytoplasm of acinar cells (Kano et al., 2001; Motta et al., 1997), is situated at the center of the "spherical" organization of the integrated Golgi apparatus of the acinus (Figure 4D). From the MTOCs in the apical area at the center of the acinus, microtubules extend radially along the longitudinal axis of acinar cells toward the periphery of the acinus. Thus, the overall topology of the Golgi and microtubule network of a whole acinus are apparently analogous to that in a single gonadotrope (Figure 4B, D).

In summary, the overall shape of the Golgi apparatus in poorly polarized endocrine cells is theoretically a symmetrical sphere as observed in gonadotropes when the MTOC is located at the putative center of the cell with enough distance from both the nucleus and cell surface (Figure 4B). When the MTOC closely approaches the nucleus, the Golgi apparatus exposes its trans-face to the nucleus as a cap-like shape on the nucleus (Figure 4A). On the other hand, when the position of the MTOC is deviated from the putative center toward the apical cytoplasm of the cell, the Golgi apparatus possibly becomes a cup-like shape in which the trans-face is toward the apical membrane (Figure 4C). In any case, intracellular positioning of the MTOC, especially its spatial relationship with the nucleus and apical surface, is probably essential to determine not only the cellular polarity but also the overall shape and organization of the Golgi apparatus. The ball-like shape of the Golgi apparatus in pituitary gonadotropes can be regarded as the ideal shape in poorly polarized endocrine cells, and will be a good starting point to consider the theoretical background for the diversity of Golgi organization in various differentiated cells in vivo.

\section{Concluding remarks and perspectives}

The Golgi apparatus in pituitary gonadotropes is spherical and its trans-side is facing the inside of the sphere, where the MTOC is situated in the cell. Although the spherical shape 
and cis/trans direction of the Golgi apparatus are apparently peculiar, the symmetrical organization is rather ideal for poorly polarized endocrine cells, considering the orientation and isotropic architecture of the microtubule network in the cell and the accumulated findings on the contextual usage of microtubule-dependent motors and transporting membrane carriers around the Golgi apparatus (Allan et al., 2002; Murshid and Presley, 2004; Thyberg and Moskalewski, 1999).

The highly symmetrical organization is also advantageous for experimental purposes because the anomalous shift from the symmetrical shape can be sensitively detected under experimental conditions. Because the functional states of gonadotropes in experimental animals can be reproducibly modulated by established methods such as castration and administration of GnRH analogues or sex steroids, monitoring the structural changes of the Golgi apparatus in gonadotropes after experimental perturbation of the hypothalamic-pituitary-gonadal axis may provide a clue to clarify the mechanisms that regulate biogenesis and maintenance of the Golgi apparatus.

On the other hand, the close relationship between the intracellular location of the MTOC and overall organization of the Golgi apparatus indicates the significance of MTOC positioning in the cell (de Forges et al., 2012; Sütterlin and Colanzi, 2010; Yadav and Linstedt, 2011). Elucidation of the mechanisms that regulate the positioning of the MTOC in well-differentiated cells will also provide a clue to the theoretical background behind the diversity of the shape and organization of the Golgi apparatus in vivo. 


\section{References}

Addison, W.H.F., 1917. The cell-changes in the hypophysis of the albino rat, after castration. J. Comp. Neurol. 28, 441-463.

Allan, B.B., Balch, W.E., 1999. Protein sorting by directed maturation of Golgi compartments. Science 285, 63-66.

Allan, V.J., Thompson, H.M., Mcniven, M.A., 2002. Motoring around the Golgi. Nat. Cell Biol. 4, E236-242.

Appenzeller-Herzog, C., Hauri, H.-P., 2006. The ER-Golgi intermediate compartment (ERGIC): In search of its identity and function. J. Cell Sci. 119, 2173-83.

Beams, H.W., Kessel, R.G., 1968. The Golgi apparatus: Structure and function. Int. Rev. Cytol. 23, 209-276.

Bliss, S.P., Navratil, A.M., Xie, J., Roberson, M.S., 2010. GnRH signaling, the gonadotrope and endocrine control of fertility. Front. Neuroendocrinol. 31, 322-340.

Blocker, A., Severin, F.F., Burkhardt, J.K., Bingham, J.B., Yu, H., Olivo, J.C., Schroer, T.A., Hyman, A.A., Griffiths, G., 1997. Molecular requirements for bi-directional movement of phagosomes along microtubules. J. Cell Biol. 137, 113-129.

Bochimoto, H., Koga, D., Sakai, Y., Hira, Y, Hosaka, M., Ushiki, T., Watanabe, T., 2013. Sustained treatment with a GnRH agonist (leuprorelin) affects the ultrastructural characteristics of membranous organelles in male rat pituitary gonadotropes. Arch. Histol. Cytol. (in press)

Brogden, R.N., Buckley, M.M., Ward, A., 1990. Buserelin. A review of its pharmacodynamic and pharmacokinetic properties, and clinical profile. Drugs 39, 399-437.

Brownhill, K., Wood, L., Allan, V., 2009. Molecular motors and the Golgi complex: Staying put and moving through. Semin. Cell Dev. Biol. 20, 784-792. 
Burkhardt, J.K., Echeverri, C.J., Nilsson, T., Vallee, R.B., 1997. Overexpression of the dynamitin (p50) subunit of the dynactin complex disrupts dynein-dependent maintenance of membrane organelle distribution. J. Cell Biol. 139, 469-484.

Chanat, E., Cozzi, M.G., Sion, B., De Monti, M., Zanini, A., Duval, J., 1988. The gonadotrope polypeptide (GP 87) released from pituitary cells under luteinizing hormone-releasing hormone stimulation is a secretogranin II form. Biochimie 70, 1361-1368.

Clermont, Y., Rambourg, A., Hermo, L., 1995. Trans-Golgi network (TGN) of different cell types: Three-dimensional structural characteristics and variability. Anat. Rec. 242, 289-301.

Cole, N.B., Lippincott-Schwartz, J., 1995. Organization of organelles and membrane traffic by microtubules. Curr. Opin. Cell Biol. 7, 55-64.

Conn, P.M., Crowley, W.F., Jr., 1994. Gonadotropin-releasing hormone and its analogs. Annu. Rev. Med. 45, 391-405.

Costoff, A., 1973. Ultrastructure of rat adenohypophysis. Correlation with function. Academic Press, New York.

Cozzi, M.G., Zanini, A., 1986. Sulfated LH subunits and a tyrosine-sulfated secretory protein (secretogranin II) in female rat adenohypophyses: Changes with age and stimulation of release by LHRH. Mol. Cell. Endocrinol. 44, 47-54.

Dalton, A.J., Felix, M.D., 1954. Cytologic and cytochemical characteristics of the Golgi substance of epithelial cells of the epididymis in situ, in homogenates and after isolation. Am. J. Anat. 94, 171-207.

De Forges, H., Bouissou, A., Perez, F., 2012. Interplay between microtubule dynamics and intracellular organization. Int. J. Biochem. Cell Biol. 44, 266-274. 
De Matteis, M.A., Luini, A., 2008. Exiting the Golgi complex. Nat. Rev. Mol. Cell Biol. 9, 273-284.

Dobkin-Bekman, M., Rahamin-Ben Navi, L., Shterntal, B., Sviridonov, L., Przedecki, F., Naidich-Exler, M., Brodie, C., Seger, R., Naor, Z., 2010. Differential role of PKC isoforms in GnRH and phorbol 12-myristate 13-acetate activation of extracellular signal-regulated kinase and jun n-terminal kinase. Endocrinology 151, 4894-4907.

Dorner, C., Ciossek, T., Muller, S., Moller, P.H., Ullrich, A., Lammers, R., 1998.

Characterization of KIF1c, a new kinesin-like protein involved in vesicle transport from the Golgi apparatus to the endoplasmic reticulum. J. Biol. Chem. 273, 20267-20275.

Drubin, D.G., Nelson, W.J., 1996. Origins of cell polarity. Cell 84, 335-344.

Ellison, E.T., Wolfe, J.M., 1934. Effect of castration on the anterior hypophysis of the female rat. Endocrinology 18, 555-575.

Emery, G., Gruenberg, J., Rojo, M., 1999. The p24 family of transmembrane proteins at the interface between endoplasmic reticulum and Golgi apparatus. Protoplasma 207, 24-30.

Engel, J.B., Schally, A.V., 2007. Drug insight: Clinical use of agonists and antagonists of luteinizing-hormone-releasing hormone. Nat. Clin. Pract. Endocrinol. Metab. 3, 157-167.

Farquhar, M.G., Palade, G.E., 1981. The Golgi apparatus (complex)-(1954-1981)-from artifact to center stage. J. Cell Biol. 91, 77s-103s.

Farquhar, M.G., Palade, G.E., 1998. The Golgi apparatus: 100 years of progress and controversy. Trends. Cell Biol. 8, 2-10. 
Farquhar, M.G., Rinehart, J.F., 1954. Electron microscopic studies of the anterior pituitary gland of castrate rats. Endocrinology 54, 516-541.

Feinstein, T.N., Linstedt, A.D., 2008. Grasp55 regulates Golgi ribbon formation. Mol. Biol. Cell 19, 2696-2707.

Gennerich, A., Vale, R.D., 2009. Walking the walk: How kinesin and dynein coordinate their steps. Curr. Opin. Cell Biol. 21, 59-67.

Glick, B.S., Elston, T., Oster, G., 1997. A cisternal maturation mechanism can explain the asymmetry of the Golgi stack. FEBS Lett. 414, 177-181.

Golgi, C., 1898a. Sur la structure des cellules nerveuses des ganglions spinaux. Arch. Ital. Biol. 30, 278-286.

Golgi, C., 1898b. Sur la structure des cellulesnerveuses. Arch. Ital. Biol. 30, 60-71.

Goodson, H.V., Valetti, C., Kreis, T.E., 1997. Motors and membrane traffic. Curr. Opin. Cell Biol. 9, 18-28.

Griffiths, G., Simons, K., 1986. The trans Golgi network: Sorting at the exit site of the Golgi complex. Science 234, 438-443.

Halban, P.A., Irminger, J.C., 1994. Sorting and processing of secretory proteins. Biochem. J. 299, 1-18.

Harada, A., Takei, Y., Kanai, Y., Tanaka, Y., Nonaka, S., Hirokawa, N., 1998. Golgi vesiculation and lysosome dispersion in cells lacking cytoplasmic dynein. J. Cell Biol. $141,51-59$.

Hehnly, H., Stamnes, M., 2007. Regulating cytoskeleton-based vesicle motility. FEBS Lett. $581,2112-2118$.

Hirokawa, N., 1998. Kinesin and dynein superfamily proteins and the mechanism of organelle transport. Science 279, 519-526. 
Hirokawa, N., Noda, Y., 2008. Intracellular transport and kinesin superfamily proteins, KIFs: Structure, function, and dynamics. Physiol. Rev. 88, 1089-1118.

Hosaka, M., Watanabe, T., Sakai, Y., Uchiyama, Y., Takeuchi, T., 2002. Identification of a chromogranin a domain that mediates binding to secretogranin iii and targeting to secretory granules in pituitary cells and pancreatic beta-cells. Mol. Biol. Cell 13, 3388-3399.

Hosaka, M., Watanabe, T., Yamauchi, Y., Sakai, Y., Suda, M., Mizutani, S., Takeuchi, T., Isobe, T., Izumi, T., 2007. A subset of p23 localized on secretory granules in pancreatic beta-cells. J. Histochem. Cytochem. 55, 235-245.

Hunt, S.D., Stephens, D.J., 2011. The role of motor proteins in endosomal sorting. Biochem. Soc. Trans. 39, 1179-1184.

Huttner, W.B., 1988. Tyrosine sulfation and the secretory pathway. Annu. Rev. Physiol. 50, 363-376.

Jaulin, F., Xue, X., Rodriguez-Boulan, E., Kreitzer, G., 2007. Polarization-dependent selective transport to the apical membrane by KIF5b in MDCK cells. Dev. Cell 13, $511-522$

Jesch, S.A., Lewis, T.S., Ahn, N.G., Linstedt, A.D., 2001. Mitotic phosphorylation of Golgi reassembly stacking protein 55 by mitogen-activated protein kinase ERK2. Mol. Biol. Cell 12, 1811-1817.

Kano, A., Hagiwara, H., Takata, K., Mogi, K., 2001. Immunolocalization of centriole-associated striated rootlets in human submandibular gland cells with and without solitary cilia. Histochem. J. 33, 613-620.

Klumperman, J., 2011. Architecture of the mammalian Golgi. Cold Spring Harb. Perspect. Biol. 3, a005181. 
Koga, D., Ushiki, T., 2006. Three-dimensional ultrastructure of the Golgi apparatus in different cells: High-resolution scanning electron microscopy of osmium-macerated tissues. Arch. Histol. Cytol. 69, 357-374.

Kreitzer, G., Marmorstein, A., Okamoto, P., Vallee, R., Rodriguez-Boulan, E., 2000. Kinesin and dynamin are required for post-Golgi transport of a plasma-membrane protein. Nat. Cell Biol. 2, 125-127.

Kurihara, H., Uchida, K., 1987. Distribution of microtubules and microfilaments in exocrine (ventral prostatic epithelial cells and pancreatic exocrine cells) and endocrine cells (cells of the adenohypophysis and islets of Langerhans). The relationship between cytoskeletons and epithelial-cell polarity. Histochemistry 87, 223-227.

Kurosumi, K., Oota, Y., 1968. Electron microscopy of two types of gonadotrophs in the anterior pituitary glands of persistent estrous and diestrous rats. Z. Zellforsch. Mikrosk. Anat. 85, 34-46.

Lawrence, C.J., Dawe, R.K., Christie, K.R., Cleveland, D.W., Dawson, S.C., Endow, S.A., Goldstein, L.S., Goodson, H.V., Hirokawa, N., Howard, J., Malmberg, R.L., Mcintosh, J.R., Miki, H., Mitchison, T.J., Okada, Y., Reddy, A.S., Saxton, W.M., Schliwa, M., Scholey, J.M., Vale, R.D., Walczak, C.E., Wordeman, L., 2004. A standardized kinesin nomenclature. J. Cell Biol. 167, 19-22.

Lin, C.Y., Madsen, M.L., Yarm, F.R., Jang, Y.J., Liu, X., Erikson, R.L., 2000. Peripheral Golgi protein grasp65 is a target of mitotic polo-like kinase (Plk) and cdc2. Proc. Natl. Acad. Sci. USA 97, 12589-12594.

Lippincott-Schwartz, J., 1998. Cytoskeletal proteins and Golgi dynamics. Curr. Opin. Cell Biol. 10, 52-59. 
Lippincott-Schwartz, J., Cole, N.B., Marotta, A., Conrad, P.A., Bloom, G.S., 1995. Kinesin is the motor for microtubule-mediated Golgi-to-ER membrane traffic. J. Cell Biol. 128, 293-306.

Loubery, S., Wilhelm, C., Hurbain, I., Neveu, S., Louvard, D., Coudrier, E., 2008. Different microtubule motors move early and late endocytic compartments. Traffic 9, 492-509.

Lowe, M., 2011. Structural organization of the Golgi apparatus. Curr. Opin. Cell Biol. 23, $85-93$.

Marsh, B.J., 2005. Lessons from tomographic studies of the mammalian Golgi. Biochim. Biophys. Acta 1744, 273-292.

Marsh, B.J., Howell, K.E., 2002. The mammalian Golgi--complex debates. Nat. Rev. Mol. Cell Biol. 3, 789-795.

Marsh, B.J., Volkmann, N., Mcintosh, J.R., Howell, K.E., 2004. Direct continuities between cisternae at different levels of the Golgi complex in glucose-stimulated mouse islet beta cells. Proc. Natl. Acad. Sci. USA 101, 5565-5570.

Martinez-Alonso, E., Tomas, M., Martinez-Menarguez, J.A., 2013. Morpho-functional architecture of the Golgi complex of neuroendocrine cells. Front. Endocrinol. 4, 41.

McArdle, C.A., Franklin, J., Green, L., Hislop, J.N., 2002. Signalling, cycling and desensitisation of gonadotrophin-releasing hormone receptors. J. Endocrinol. 173, $1-11$.

Meads, T., Schroer, T.A., 1995. Polarity and nucleation of microtubules in polarized epithelial cells. Cell Motil. Cytoskeleton 32, 273-288.

Mellman, I., Simons, K., 1992. The Golgi complex: In vitro veritas? Cell 68, 829-840.

Millar, R.P., Lu, Z.L., Pawson, A.J., Flanagan, C.A., Morgan, K., Maudsley, S.R., 2004. Gonadotropin-releasing hormone receptors. Endocr. Rev. 25, 235-275. 
Mogelsvang, S., Marsh, B.J., Ladinsky, M.S., Howell, K.E., 2004. Predicting function from structure: $3 \mathrm{~d}$ structure studies of the mammalian Golgi complex. Traffic 5, 338-345. Moremen, K.W., Tiemeyer, M., Nairn, A.V., 2012. Vertebrate protein glycosylation: Diversity, synthesis and function. Nat. Rev. Mol. Cell Biol. 13, 448-462.

Motta, P.M., Macchiarelli, G., Nottola, S.A., Correr, S., 1997. Histology of the exocrine pancreas. Microsc. Res. Tech. 37, 384-398.

Murshid, A., Presley, J.F., 2004. ER-to-Golgi transport and cytoskeletal interactions in animal cells. Cell. Mol. Life Sci. 61, 133-145.

Müsch, A., 2004. Microtubule organization and function in epithelial cells. Traffic 5, 1-9.

Nakagawa, T., Setou, M., Seog, D., Ogasawara, K., Dohmae, N., Takio, K., Hirokawa, N., 2000. A novel motor, KIF13a, transports mannose-6-phosphate receptor to plasma membrane through direct interaction with AP-1 complex. Cell 103, 569-581.

Naor, Z., 2009. Signaling by G-protein-coupled receptor (GPCR): Studies on the GnRH receptor. Front. Neuroendocrinol. 30, 10-29.

Niehrs, C., Beisswanger, R., Huttner, W.B., 1994. Protein tyrosine sulfation, 1993--an update. Chem. Biol. Interact. 92, 257-271.

Opat, A.S., Van Vliet, C., Gleeson, P.A., 2001. Trafficking and localisation of resident Golgi glycosylation enzymes. Biochimie 83, 763-773.

Pelham, H.R., 2001. Traffic through the Golgi apparatus. J. Cell Biol. 155, 1099-1101.

Persico, A., Cervigni, R.I., Barretta, M.L., Colanzi, A., 2009. Mitotic inheritance of the Golgi complex. FEBS Lett. 583, 3857-3862.

Pfister, K.K., Fisher, E.M., Gibbons, I.R., Hays, T.S., Holzbaur, E.L., Mcintosh, J.R., Porter, M.E., Schroer, T.A., Vaughan, K.T., Witman, G.B., King, S.M., Vallee, R.B., 2005. Cytoplasmic dynein nomenclature. J. Cell Biol. 171, 411-413. 
Pielecka, J., Moenter, S.M., 2006. Effect of steroid milieu on gonadotropin-releasing hormone-1 neuron firing pattern and luteinizing hormone levels in male mice. Biol. Reprod. 74, 931-937.

Plosker, G.L., Brogden, R.N., 1994. Leuprorelin. A review of its pharmacology and therapeutic use in prostatic cancer, endometriosis and other sex hormone-related disorders. Drugs 48, 930-967.

Preisinger, C., Barr, F.A., 2005. Kinases regulating Golgi apparatus structure and function. Biochem. Soc. Symp. 72, 15-30.

Presley, J.F., Cole, N.B., Schroer, T.A., Hirschberg, K., Zaal, K.J., Lippincott-Schwartz, J., 1997. ER-to-Golgi transport visualized in living cells. Nature 389, 81-85.

Puthenveedu, M.A., Bachert, C., Puri, S., Lanni, F., Linstedt, A.D., 2006. Gm130 and GRASP65-dependent lateral cisternal fusion allows uniform Golgi-enzyme distribution. Nat. Cell Biol. 8, 238-248.

Puthenveedu, M.A., Linstedt, A.D., 2005. Subcompartmentalizing the Golgi apparatus. Curr. Opin. Cell Biol. 17, 369-375.

Rambourg, A., Clermont, Y., 1990. Three-dimensional electron microscopy: Structure of the Golgi apparatus. Eur. J. Cell Biol. 51, 189-200.

Rambourg, A., Clermont, Y., 1997. Three-dimensional structure of the Golgi apparatus in mammalian cells. In: Berger, E.G., Roth, J. eds. The Golgi apparatus. Birkhäuser Verlag, Basel, pp. 37-61.

Rambourg, A., Clermont, Y., Chretien, M., Olivier, L., 1992. Formation of secretory granules in the Golgi apparatus of prolactin cells in the rat pituitary gland: A stereoscopic study. Anat. Rec. 232, 169-179. 
Rambourg, A., Clermont, Y., Chretien, M., Olivier, L., 1993. Modulation of the Golgi apparatus in stimulated and nonstimulated prolactin cells of female rats. Anat. Rec. $235,353-362$.

Rambourg, A., Clermont, Y., Hermo, L., 1981. Three-dimensional structure of the Golgi apparatus. Methods Cell Biol. 23, 155-166.

Rojo, M., Pepperkok, R., Emery, G., Kellner, R., Stang, E., Parton, R.G., Gruenberg, J., 1997. Involvement of the transmembrane protein p23 in biosynthetic protein transport. J. Cell Biol. 139, 1119-1135.

Ruf, F., Fink, M.Y., Sealfon, S.C., 2003. Structure of the GnRH receptor-stimulated signaling network: Insights from genomics. Front. Neuroendocrinol. 24, 181-199.

Schindler, R., Itin, C., Zerial, M., Lottspeich, F., Hauri, H.P., 1993. ERGIC-53, a membrane protein of the ER-Golgi intermediate compartment, carries an ER retention motif. Eur. J. Cell. Biol. 61, 1-9.

Schliwa, M., Woehlke, G., 2003. Molecular motors. Nature 422, 759-765.

Severinghaus, A.E., 1933. A cytological study of the anterior pituitary of the rat, with special reference to the Golgi apparatus and to cell relationship. Anat. Rec. 57, 149-175.

Severinghaus, A.E., 1937. Cellular changes in the anterior hypophysis with special reference to its secretory activities. Physiol. Rev. 17, 556-588.

Sjöstrand, F.S., Hanzon, V., 1954. Ultrastructure of Golgi apparatus of exocrine cells of mouse pancreas. Exp. Cell Res. 7, 415-429.

Stanton, R.A., Gernert, K.M., Nettles, J.H., Aneja, R., 2011. Drugs that target dynamic microtubules: A new molecular perspective. Med. Res. Rev. 31, 443-481. 
Stauber, T., Simpson, J.C., Pepperkok, R., Vernos, I., 2006. A role for kinesin-2 in COPI-dependent recycling between the ER and the Golgi complex. Curr. Biol. 16, $2245-2251$.

Storrie, B., 2005. Maintenance of Golgi apparatus structure in the face of continuous protein recycling to the endoplasmic reticulum: Making ends meet. Int. Rev. Cytol. 244, $69-94$.

Sütterlin, C., Colanzi, A., 2010. The Golgi and the centrosome: Building a functional partnership. J. Cell Biol. 188, 621-628.

Tanaka, K., Fukudome, H., 1991. Three-dimensional organization of the Golgi complex observed by scanning electron microscopy. J. Electron Microsc. Tech. 17, 15-23.

Tanaka, K., Mitsushima, A., 1984. A preparation method for observing intracellular structures by scanning electron microscopy. J. Microsc. 133, 213-222.

Tanaka, K., Mitsushima, A., Fukudome, H., Kashima, Y., 1986. Three-dimensional architecture of the Golgi complex observed by high resolution scanning electron microscopy. J. Submicrosc. Cytol. 18, 1-9.

Thyberg, J., Moskalewski, S., 1999. Role of microtubules in the organization of the Golgi complex. Exp. Cell Res. 246, 263-279.

Vallee, R.B., Williams, J.C., Varma, D., Barnhart, L.E., 2004. Dynein: An ancient motor protein involved in multiple modes of transport. J. Neurobiol. 58, 189-200.

Varadi, A., Ainscow, E.K., Allan, V.J., Rutter, G.A., 2002. Involvement of conventional kinesin in glucose-stimulated secretory granule movements and exocytosis in clonal pancreatic beta-cells. J. Cell Sci. 115, 4177-4189.

Vinke, F.P., Grieve, A.G., Rabouille, C., 2011. The multiple facets of the Golgi reassembly stacking proteins. Biochem. J. 433, 423-433. 
Wang, Y., Seemann, J., Pypaert, M., Shorter, J., Warren, G., 2003. A direct role for GRASP65 as a mitotically regulated Golgi stacking factor. EMBO J. 22, 3279-3290.

Watanabe, T., Banno, T., Jeziorowski, T., Ohsawa, Y., Waguri, S., Grube, D., Uchiyama, Y., 1998. Effects of sex steroids on secretory granule formation in gonadotropes of castrated male rats with respect to granin expression. Endocrinology 139, 2765-2773.

Watanabe, T., Jeziorowski, T., Wuttke, W., Grube, D., 1993. Secretory granules and granins in hyperstimulated male rat gonadotropes. J. Histochem. Cytochem. 41, 1801-1812.

Watanabe, T., Sakai, Y., Koga, D., Bochimoto, H., Hira, Y., Hosaka, M., Ushiki, T., 2012. A unique ball-shaped Golgi apparatus in the rat pituitary gonadotrope: Its functional implications in relation to the arrangement of the microtubule network. J. Histochem. Cytochem. 60, 588-602.

Watanabe, T., Uchiyama, Y., Grube, D., 1991. Topology of chromogranin a and secretogranin II in the rat anterior pituitary: Potential marker proteins for distinct secretory pathways in gonadotrophs. Histochemistry 96, 285-293.

Watson, P., Forster, R., Palmer, K.J., Pepperkok, R., Stephens, D.J., 2005. Coupling of ER exit to microtubules through direct interaction of COPII with dynactin. Nat. Cell Biol. 7, 48-55.

Wolfe, J.M., Brown, A.D., 1942. Action of diethylstilbestrol on cytological characteristics of anterior pituitaries of female rats, together with certain observations on the effect of castration. Endocrinology 31, 467-478.

Xiang, Y., Wang, Y., 2010. GRASP55 and GRASP65 play complementary and essential roles in Golgi cisternal stacking. J. Cell Biol. 188, 237-251.

Yadav, S., Linstedt, A.D., 2011. Golgi positioning. Cold Spring Harb. Perspect. Biol. 3, a005322. 


\section{Figure legends}

Figure 1. Organization of the Golgi and microtubular network in pituitary gonadotropes of male rats. (A, B) Intracellular localizations of the Golgi apparatus (immunolabeled with an anti-GM130 antibody; green pseudocolor), the MTOC (immunolabeled with an anti- $\gamma$-tubulin ( $\gamma$-Tub) antibody; red), and the nucleus (stained with DAPI; blue) in a thick section of an anterior pituitary gland (A). Gonadotropes were identified by immunolabeling with an anti-LH antibody (white pseudocolor). A three-dimensionally reconstructed image of the gonadotrope indicated by a white square in (A) is demonstrated in a stereo pair at a higher magnification (B; the immunopositive signal for $\mathrm{LH}$ is omitted in this panel; see also supplementary movie S1 and S2). Bars $=10 \mu \mathrm{m}$. (C-E) Immunocytochemical localizations of $\mathrm{BiP}(\mathrm{C}$; green), GM130 (D; green), and $\gamma$-adaptin (E; green) in three adjacent semi-thin sections (thickness: $1 \mu \mathrm{m}$ each) of rat anterior pituitary gland. These semi-thin sections were simultaneously immunostained with anti-LH (blue) and anti-TGN38 (red) antibodies. Bar $=$ $10 \mu \mathrm{m}$. (F, G) Intracellular localizations of the Golgi apparatus (immunolabeled with an anti-TGN38 antibody; green), the MTOC (immunolabeled with an anti- $\gamma$-tubulin ( $\gamma$-Tub) antibody; red), realatively stable microtubules (immunolabeled with an anti-acetylated $\alpha$-tubulin (Ac- $\alpha$-Tub); white), and the nucleus (stained with DAPI; blue) in a thick section of an anterior pituitary gland (F). An optical slice at the equatorial position $(\mathrm{F})$ and a pair of three-dimensionally reconstructed images $(\mathrm{G})$ of the spherical Golgi apparatus are shown (the signal for TGN38 staining is omitted in G; see also supplementary movie S3 and S4). Bar= $10 \mu \mathrm{m}$. For detailed Materials and Methods, see Watanabe et al. (2012).

Figure 2. Schematic representation of the organization of the Golgi and microtubular network within pituitary gonadotropes (A). The contextual usage of microtubule-dependent 
motors and membrane carriers in pre- and post-Golgi compartments is demonstrated in (B) and $(\mathrm{C})$, respectively.

Figure 3. Effects of the GnRH agonist leuprorelin on the organization of the Golgi in gonadotropes. (A, C) Thick cryosections $(10 \mu \mathrm{m})$ of anterior pituitary glands prepared from control rats (A) and at 1 day $(C$; Leu_1d) after receiving a depot formulation of leuprorelin were immunostained simultaneously with mouse monoclonal anti-GM130 (Alexa Fluor 594; red pseudocolor), sheep polyclonal anti-TGN38 (Alexa Fluor 488; green), and rabbit polyclonal anti-LH (Pacific Blue; blue) antibodies. Bars $=1 \mu \mathrm{m} .(\mathrm{B}, \mathrm{D})$ Osmium-macerated pituitary tissues of rats under the experimental condition described above were also viewed under a scanning electron microscope. In support of the immunocytochemical findings $(A, C)$, typical gonadotropes of non-treated control rats contain a ball-like Golgi apparatus (B; green), whereas gonadotropes of leuprorelin-treated rats contain numerous isolated Golgi mini-stacks scattered in the cytoplasm. Blue: nucleus. For detailed Materials and Methods, see Bochimoto et al., (2013). Bars $=1 \mu \mathrm{m}$.

Figure 4. The putative relationship between positioning of the MTOC and overall shape of the Golgi apparatus in pituitary endocrine (A, B) and exocrine acinar (C) cells. In addition to the Golgi organization of individual acinar cells (C), that of a whole acinus is also shown (D). Note that the trans-side of the Golgi apparatus is not always facing the plasma membrane, but rather faces the MTOC in cells.

Supplementary Movie S1. The series of the original data (thickness of each optical section: $0.33 \mu \mathrm{m}$ ) for three-dimensional reconstruction of the gonadotrope demonstrated in Figure 1B 
are additionally shown in a tomographic movie form. The z-axial distance of each optically sliced section from the bottom of the specimen is indicated in the left-lower corner of the movie clip. Pseudocolors are assigned similarly to those in Figure 1A (white pseudocolor: anti-LH to identify the gonadotrope; red: anti- $\gamma$-tubulin for the MTOC; green: anti-GM130 for the Golgi apparatus; blue: DAPI for the nucleus).

Supplementary Movie S2. 3D-rotation movie of the gonadotrope demonstrated in Figure 1B. Note that the MTOC immunolabeled with an anti- $\gamma$-tubulin antobody (red) is situated at the center of the sperical Golgi (immunostained with an anti-GM130 antibody; green) in the gonadotrope (immunostained with an anti-LH antibody; white).

Supplementary Movie S3. The series of the original data (thickness of each optical section: $0.33 \mu \mathrm{m})$ for three-dimensional reconstruction of the cells demonstrated in Figure $1 \mathrm{G}$ are additionally shown in a tomographic movie form. The z-axial distance of each optically sliced section from the bottom of the specimen is indicated in the left-lower corner of the movie clip. Pseudocolors are assigned similarly to those in Figure 1F (white pseudocolor: anti-acetylated $\alpha$-tubulin for relatively stable bundles of microtubules; red: anti- $\gamma$-tubulin for the MTOC; green: anti-TGN38 for the Golgi apparatus; blue: DAPI for the nucleus).

Supplementary Movie S4. 3D-rotation movie of the cells demonstrated in Figure 1G. Note that relatively stable microtubules (immunolabeled with an anti-acetylated $\alpha$-tubulin antibody; white) are radiating from the MTOC (immunolabeled with an anti- $\gamma$-tubulin antobody; red) situated at the center of the sperical Golgi apparatus (immunostained with an 
anti-TGN38 antibody; green). Some bundles of the microtubules cover also tangentially the spherical Golgi. 
$\oplus$

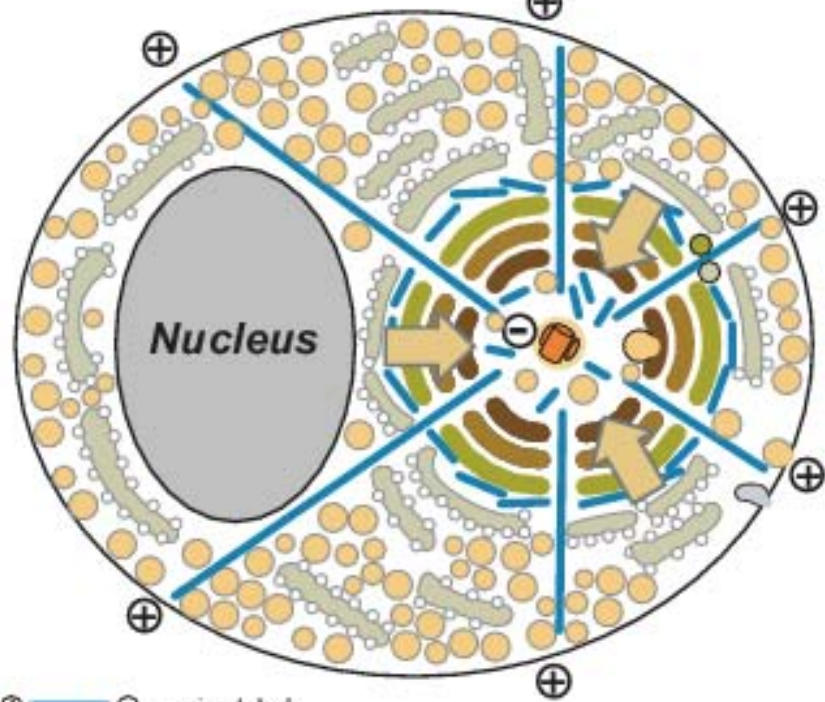

$\oplus$

$\Theta$ minus end of microtubule

(1) plus end of microtubule

\&umar dynein-dependent movement

$\longrightarrow \quad$ kinesin/KIFs -dependent movement

8 MTOC/ centrosome ( $\gamma$ tubulin positive) cis? trans

(frans Golgi apparatus

rER: rough endoplasmic reticulum

A
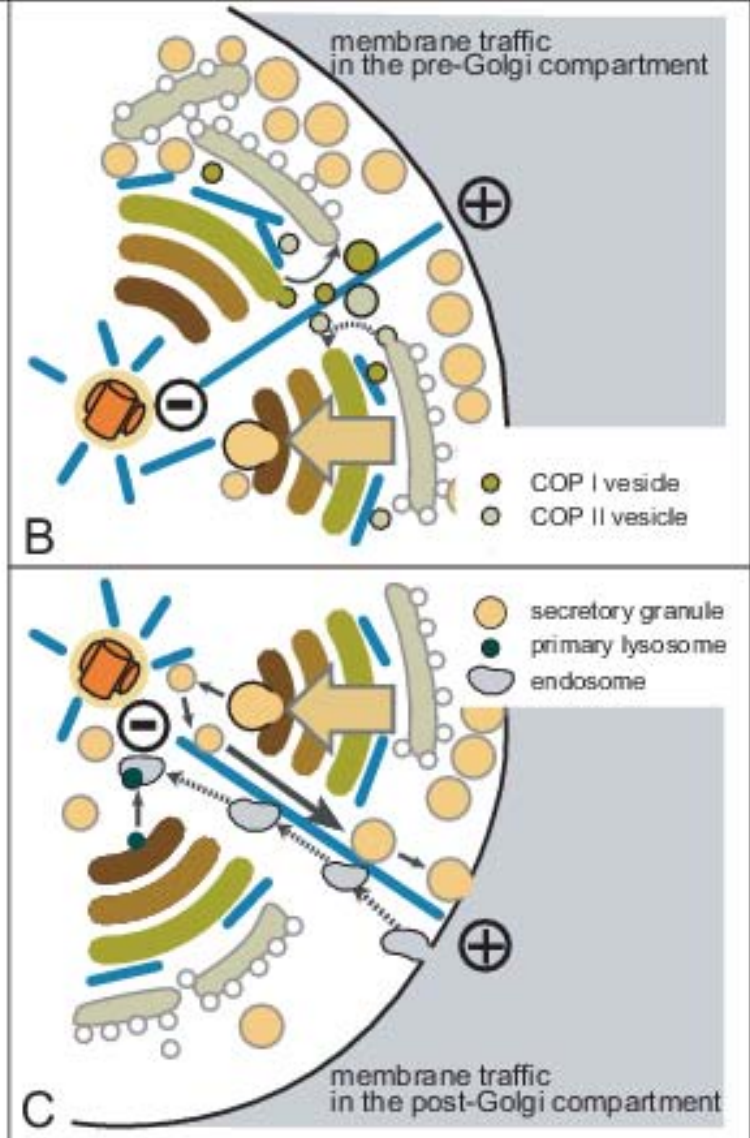


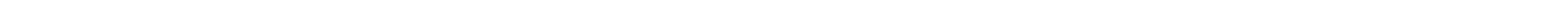


poorly polarized endocrine cell (mammotrope/ somatotrope)

Cap-like shape Golgi on the nucleus

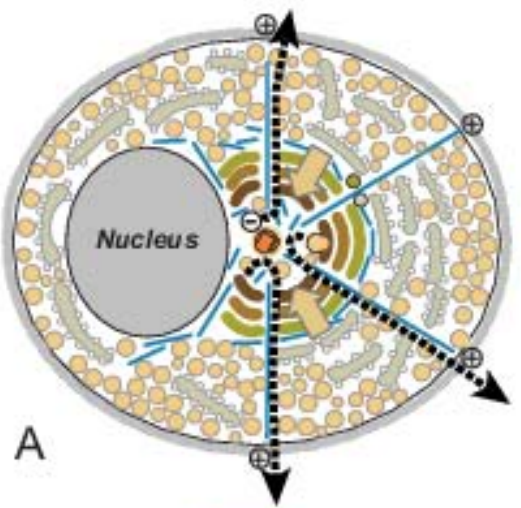

$\oplus$ $\Theta$ microtubule

6 MTOC / centrosome ( $\gamma$ tubulin positive)

$\lim$ cis $\int^{\text {trans }}$

rER: rough endoplasmic reticulum

secretory granule

$\square$ flow of secretory proteins from the rER

fwe. flow of secretory proteins from the trans-Golgi network basal lamina polarized exocrine acinar cell

Cup-like shape Golgi open to the apical membrane
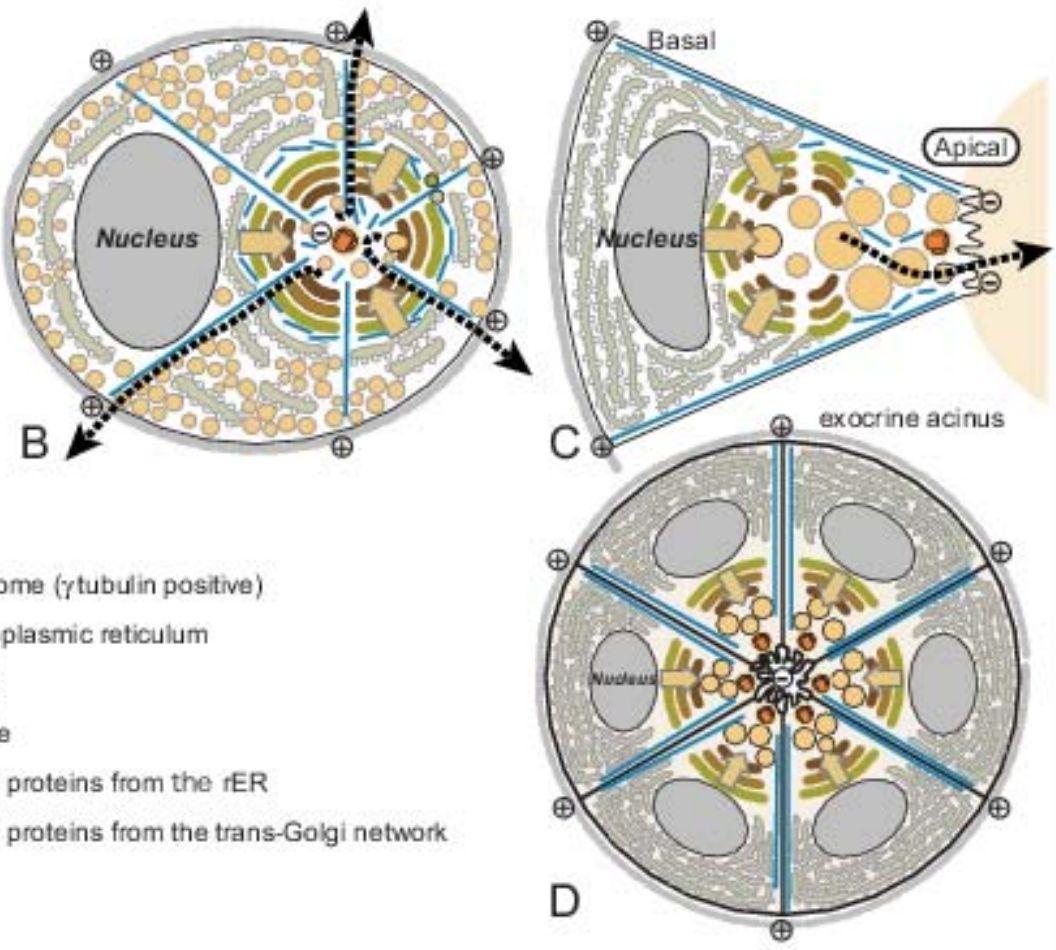
4t

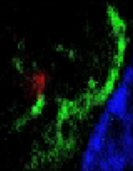

$$
\min ^{x} \times
$$

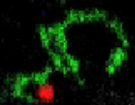




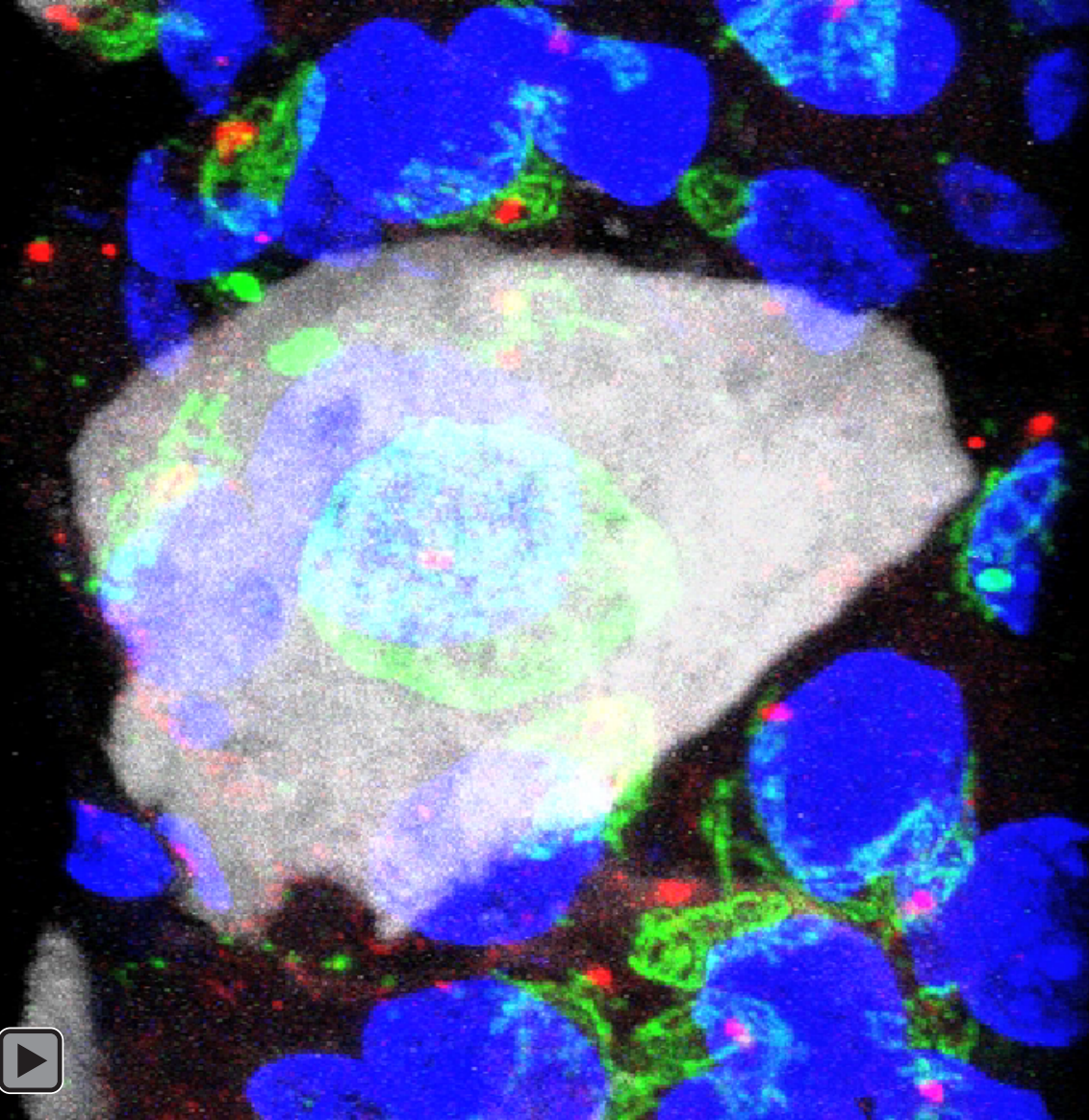


